\title{
It's all relative: how customer-perceived competitive advantage influences referral intentions
}

\author{
Martin Mende • Scott A. Thompson • \\ Christian Coenen
}

Published online: 27 July 2014

(C) Springer Science+Business Media New York 2014

\begin{abstract}
Better understanding the mechanisms that influence customer intentions to spread positive word-of-mouth (WOM) is crucial to both marketing scholars and managers. This multimethod research contributes to marketing knowledge by revealing how a firm's customer-perceived competitive advantage (CPCA) influences positive WOM intentions. Analyses of (1) cross-sectional survey data on bank customers in Germany and (2) experimental data on customers of car insurance companies in the USA reveal two crucial insights. First, CPCA influences WOM intentions in both industries, over and above numerous established antecedents of customer loyalty (e.g., satisfaction, trust, and perceived value). Second, this research demonstrates a robust and pervasive CPCA-by-satisfaction interaction effect, such that the influence of CPCA on WOM intentions increases as customer satisfaction decreases. The results show that customer-perceived competitive advantage plays an important role in shaping WOM intentions, especially among less-satisfied customers. Theoretical and managerial implications of these findings are discussed.
\end{abstract}

Keywords Word-of-mouth intentions · Competitive advantage Relationship marketing $\cdot$ Customer loyalty

\footnotetext{
M. Mende

Department of Marketing, College of Business, Florida State University, Tallahassee,

FL 32306-1110, USA

e-mail: mmende@fsu.edu

S. A. Thompson $(\bowtie)$

Marketing Department, Terry College of Business, University of Georgia, Athens, GA 30602, USA

e-mail: sat@uga.edu

C. Coenen

Services Management, Zurich University of Applied Sciences, Zurich, Switzerland

e-mail: christian.coenen@zhaw.ch
} 


\section{Introduction}

Customer intentions to recommend a company are of fundamental interest to marketers for numerous reasons. First, customer intentions to spread positive word-of-mouth (WOM) help predict business outcomes. For example, Kamakura et al. (2002) show that customers' intentions to recommend their bank help predict share-of-wallet, tenure, transactions per month, and profitability. Second, though not identical, intentions to recommend are closely co-aligned with actual recommendation behavior (de Matos and Rossi 2008). For example, analyzing the Net Promoter score, Morgan and Rego (2008, p. 533) contrast recommendation intentions and behavior and find that these variables are highly correlated $(>0.90)$, behaving "remarkably similarly when examined relative to" customer satisfaction. Third, while research has identified important antecedents of WOM intentions, most prominently customer satisfaction, the mechanisms that influence consumer-to-consumer recommendations are not yet fully understood (Berger and Iyengar 2012; Stephen and Lehmann 2009). Specifically, marketing scholars have called for a stronger emphasis on the influence a firm's competitive context has on customer loyalty, including WOM (Boulding et al. 2005; Kumar et al. 2006; Posavac et al. 2005).

Answering this call, we examine the effects of customer-perceived competitive advantage (CPCA) - the consumer's assessment of a firm relative to its competitors - on WOM intentions. We also consider the interplay of CPCA and satisfaction in shaping WOM intentions and predict that when satisfaction is lower, the impact of CPCA on WOM intentions is higher. Two studies support this prediction. The data reveal that CPCA interacts with satisfaction to affect WOM intentions, with the impact of CPCA on WOM intentions increasing as satisfaction decreases. To our knowledge, this research is the first to demonstrate this interaction effect for WOM intentions. Extending marketing knowledge about the drivers of WOM intentions, these findings have important theoretical and managerial implications.

\section{Conceptual development}

Research has widely used satisfaction to predict customer referrals (i.e., positive WOM) (Anderson 1998; de Matos and Rossi 2008). We extend this insight to consider the interplay of satisfaction, WOM intentions, and a firm's competitiveness.

\subsection{Satisfaction, WOM intentions, and the firm's competitive context}

The disconfirmation paradigm defines satisfaction as the outcome of a consumer's comparison between perceived and expected firm performance (Oliver 1997). The degree to which the actual performance exceeds customers' expectations helps explain their motivation to tell others about their experience. For example, in a seminal study of consumers in Sweden and the USA, Anderson (1998) reveals an asymmetric U-shape for the relationship between satisfaction and WOM (i.e., extremely dis-/satisfied customers engage in more WOM than moderately dis-/satisfied customers). Although marketing research has provided these and other important insights into the relationship between satisfaction (and other antecedents) and WOM (Brown et al. 2005; de Matos 
and Rossi 2008), little research-particularly in the area of relationship marketing-has examined the interplay of satisfaction, firm competitiveness, and WOM intentions.

Why has relationship marketing research paid little attention to the firm's competitive context? One major reason is the belief that the disconfirmation paradigm of satisfaction accounts for competition. This paradigm suggests that consumers incorporate perceptions of a firm's competitors into their expectations in two ways (Oliver 1997; Zeithaml et al. 1993). First, their awareness of existing alternatives raises the level of performance they consider adequate. Second, their expectations are influenced by promises from competitors, the WOM they receive about competitors, and their past experiences with the firm and its competitors. Despite this logic, scholars have questioned whether the satisfaction construct fully captures the competitive context and have proposed that alternative, subjective measures of competition provide insights beyond satisfaction (Dick and Basu 1994; Gale 1994; Ping 1994). Building on this idea, we examine the role of CPCA, which we define next.

While considerable debate about the definition of competitive advantage persists, we follow Duncan et al. (1998, p. 7), who define competitive advantage as "the result of an enduring value differential between the products and services of one organization and those of its competitors in the minds of customers." This definition recognizes that a firm's superior resources lead to superior financial performance only if customers perceive superior benefits (Day and Wensley 1988). Furthermore, to understand the role of competitive advantage in shaping WOM intentions, it is necessary to consider how it was gained. Firms can achieve a competitive advantage with superior products, superior customer service, and lower prices (Day and Wensley 1988; Gale 1994). Accordingly, we define CPCA as a consumer's perception of the extent to which a firm - in terms of its products, customer service, and/or pricing-is superior to alternative firms. As Fig. 1 displays, we propose a direct and indirect effect of CPCA on WOM intentions.

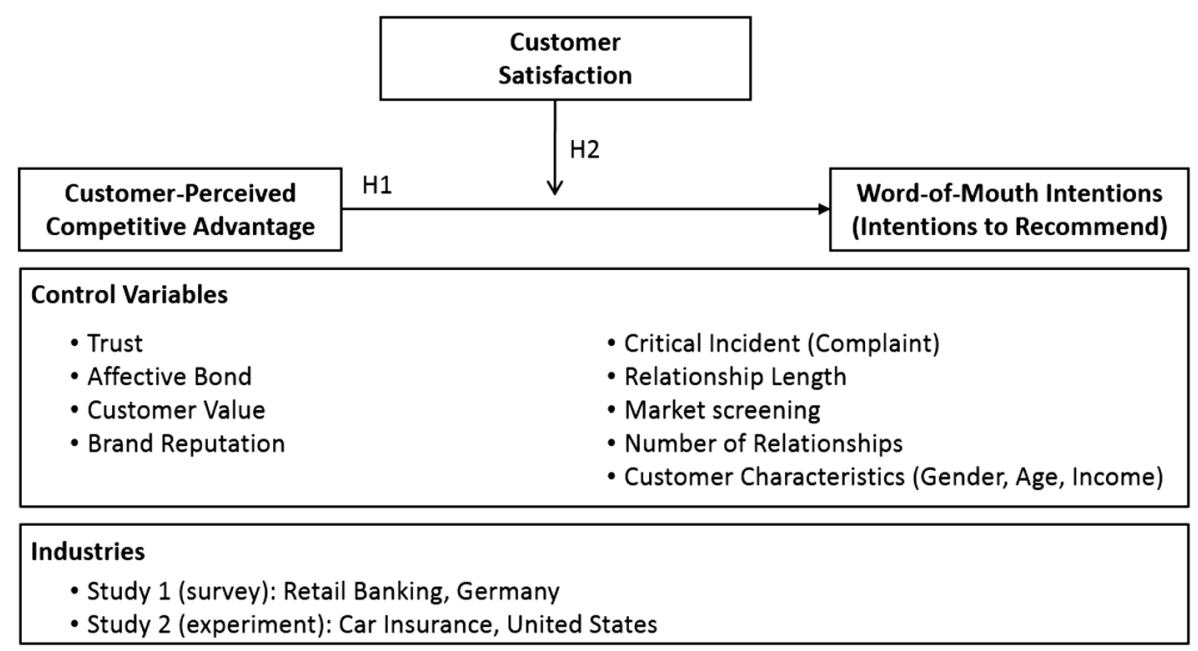

Fig. 1 Conceptual framework: how CPCA influences WOM intentions 


\subsection{The direct and indirect effect of CPCA on WOM intentions}

We propose that CPCA helps explain why consumers recommend a firm. People use metaperception to decipher how others perceive them, and they form expectations of the potential change in their own reputation resulting from their social communications (Schlenker 1980). Because WOM is social in nature (Stephen and Lehmann 2009), consumers who recommend a firm place their own social capital at risk. Notably, consumers often engage in WOM to build social capital (Stephen and Lehmann 2009), and for self-promotion and self-enhancement (Chung and Darke 2006; Wojnicki and Godes 2008). Therefore, given the social risks and benefits associated with a referral, consumers should consider CPCA such that the perception of the firm's competitive superiority should positively influence WOM intentions, over and above a consumer's satisfaction.

$H_{1}$ : CPCA has a positive effect on WOM intentions, beyond the effect of satisfaction.

Moreover, we propose an interaction such that with decreasing levels of satisfaction, consumers increasingly rely on CPCA in their WOM intentions. This prediction (1) recognizes that customers can be satisfied without assessing a firm to be superior to its competitors (i.e., satisficing), but (2) further builds on the notion that people are more likely to engage in behaviors that they believe will result in more favorable self-presentation. For example, people often adjust their social behavior, despite their privately held beliefs, if it improves their self-presentation (Chung and Darke 2006; Schlenker 1980). In our context, this does not mean that consumers must ignore their private beliefs (e.g., their satisfaction with a firm); rather, we expect them to trade off satisfaction and CPCA in light of the self-presentation linked to a referral. Relative to satisfaction, greater CPCA reduces the social risk associated with spreading positive WOM, because it represents the notion of a superior firm, rather than a merely satisfying one. Although satisficing may lead customers to repurchase from a firm that is "good enough," this mechanism is unlikely to hold for positive WOM. The construct of CPCA offers consumers a better opportunity for self-promotion than satisfaction, because recommending "the superior" rather than "the good enough" is more likely to build social capital. In parallel, recommending a firm with which one is not highly satisfied is potentially risky. However, if this firm is perceived as "the best" available alternative, the risk is offset by the belief that the best possible recommendation is being offered to others, which protects the recommender's social capital. In summary, customers can be satisfied without assessing a firm to be competitively superior (i.e., satisficing), but given the social risks associated with WOM, their motivation to rely on CPCA should increase with decreasing levels of satisfaction.

$\mathrm{H}_{2}$ : There is an interaction between CPCA and satisfaction, such that with lower levels of satisfaction, the positive relationship between CPCA and WOM intentions becomes stronger. 


\section{Study 1: Survey study on customer-bank relationships}

Study 1 tests the hypotheses using survey data on customer-bank relationships. The banking industry provides a strong research context twofold. First, essentially every consumer requires banking services. Second, selecting a bank is a nontrivial decision that has shortand long-term financial consequences; accordingly, the decision to recommend a bank carries the potential for social implications if the bank proves to be inferior.

\subsection{Research design}

A market research firm telephoned a probability sample of 5,000 customers of a medium-sized bank in Germany (hereinafter called ABC Bank). No incentive was offered to customers for participating, but the bank promoted the study with a letter sent in the mail. A total of 2,401 customers agreed to participate (response rate, $48 \%$ ). Participants completed a telephone interview that lasted approximately $10 \mathrm{~min}$. The interview began with customers' overall assessment of the bank (e.g., satisfaction), followed by service quality attributes (irrelevant to our analyses). Then, the interview covered CPCA, WOM intentions, and sociodemographics. Respondents (49.5\% female) ranged in age from 16 to $79(M=48.96$ years, $\mathrm{SD}=12.10) .{ }^{1}$ Missing values were replaced by substituting the mean value.

Measurement of CPCA Consistent with our conceptualization, we measured CPCA with four items (Appendix 1). Three items assess whether customers perceive the bank as superior to competitors in terms of products, customer service, and fees. The fourth item is a global item that asks whether the bank is superior by providing more advantages than other financial service firms the customers would consider. These measures-explicitly referencing other companies that consumers consider-account for an important insight from consumer research. Consumer preferences are context-dependent (Tversky and Simonson 1993), such that consumers' relative preferences for one option depend on both the characteristics of this option and the characteristics of available alternatives.

Measurement of dependent and control variables Appendix 1 displays the measures used in study 1. Consistent with related work (e.g., Anderson 1998), we measured WOM intentions and satisfaction with one question respectively. The analyses accounted for important covariates that can influence customer loyalty: trust and the affective bond with the organization (Garbarino and Johnson 1999; Verhoef 2003), brand reputation (Selnes 1993), and customer value, defined as the ratio of benefits to sacrifices (Zeithaml 1988). Furthermore, we controlled for negative critical incidents (complaints) (Smith and Bolton 1998), relationship length (Verhoef 2003), and demographics (gender, age, and income). Two additional covariates emphasized the competition focus of this research. First, alternatives must be explored by consumers before they can interfere with an existing relationship. Therefore, one item (called "market screening") measured the attention customers devote to monitoring alternatives. Second, we controlled for the number of bank relationships a customer had in total.

\footnotetext{
${ }^{1}$ Because not all survey questions were asked of every consumer (to keep the survey short), our analyses include 1,963 customers.
} 


\subsection{Model estimation}

The dependent measure (WOM intentions) is based on a five-point Likert scale and thus constitutes an ordinal measure (Liao 1994). When applied to ordinal dependent variables, models designed for continuous variables, such as ordinary least squares (OLS) regression, can produce misleading results (McKelvey and Zavoina 1975; Winship and Mare 1984); therefore, an ordinal logistic model (OLM) is more appropriate (Greene 2003; McKelvey and Zavoina 1975). The OLM is a latent variable model in which the underlying dependent variable, $y^{*}$, is a continuous latent variable ranging from $-\infty$ to $+\infty$ (Long 1997). The resulting structural model is

$$
\begin{aligned}
& y_{i} *=\alpha+\beta \text { CPCA }_{i}+\beta \text { Satis }_{i}+\beta \text { CPCA } \times \\
& \beta \text { Satis }_{i}+\beta \text { trust }_{i}+\beta \text { AffectBond }_{i}+ \\
& \beta \text { PerceivedValue }_{i}+\beta \text { BrandRep }_{i}+\beta \text { Market } \\
& \text { Screen }_{i}+\beta \text { NumBankSUsed }_{i}+ \\
& \beta \text { ReasonComplain }_{i}+\beta \text { Tenure }_{i}+\beta \text { Gender }_{i} \\
& +\beta \text { Age }_{i}+\beta \text { Income }_{i}+\varepsilon_{i}
\end{aligned}
$$

where $y^{*}$ is the latent dependent variable, $i$ is the respondent, and $\varepsilon$ is the random error. Because the OLM is a latent variable model, $y^{*}$-standardized $\left(\beta^{\text {Sy* }}\right)$ and fully standardized coefficients $\left(\beta^{S}\right)$ can be computed (Long 1997). The $y^{*}$-standardized coefficient $\left(\beta^{\mathrm{Sy}}\right)$ indicates the expected standard deviation change in the underlying latent variable $y^{*}$ for each unit change in an independent variable. The fully standardized coefficient $\left(\beta^{S}\right)$ indicates the expected standard deviation change in $y^{*}$ for each standard deviation change in an independent variable, holding all other variables constant (Long 1997). Following recommended practice, our interpretation of independent variables focuses on the expected changes in the latent evaluation $y^{*}$ (Long 1997).

\subsection{Results}

Table 1 provides descriptive statistics and correlations. Means and standard deviations are consistent with prior research. The coefficient alpha for the CPCA measure (0.75) exceeded the threshold level of 0.70 (Nunnally and Bernstein 1994). Although the correlation between CPCA and satisfaction was only moderate $(r=0.360)$, we examined the results for evidence of multicollinearity. In logistic regression models, multicollinearity can increase the standard errors and create convergence problems, although the coefficients remain unbiased (Menard 2002). The results of our OLM model do not show any of these symptoms, and standard errors do not exceed values of $2.0 .^{2}$

\footnotetext{
${ }^{2}$ We also conducted a factor analysis (principal component analysis with an oblique rotation) to explore the discriminant validity between the four CPCA items and the global satisfaction item. This analysis resulted in a two-factor solution. The two factors were moderately correlated $(r=0.37)$. The final rotated solution explained $66.91 \%$ of the total variance in the items (CPCA accounted for $51.23 \%$ and satisfaction for $15.68 \%$ of the total variance). The factor loadings displayed a clean factor structure. The magnitude of factor loadings was satisfactory and meaningful, with loadings on the target factor (CPCA) ranging from 0.61 to 0.86 . A similar analysis using the data from study 2 (four CPCA items and three satisfaction items) also extracted two factors and showed a clean factor structure and meaningful loadings. Taken together, these analyses suggest that satisfaction and CPCA represent distinct constructs and should be treated separately.
} 


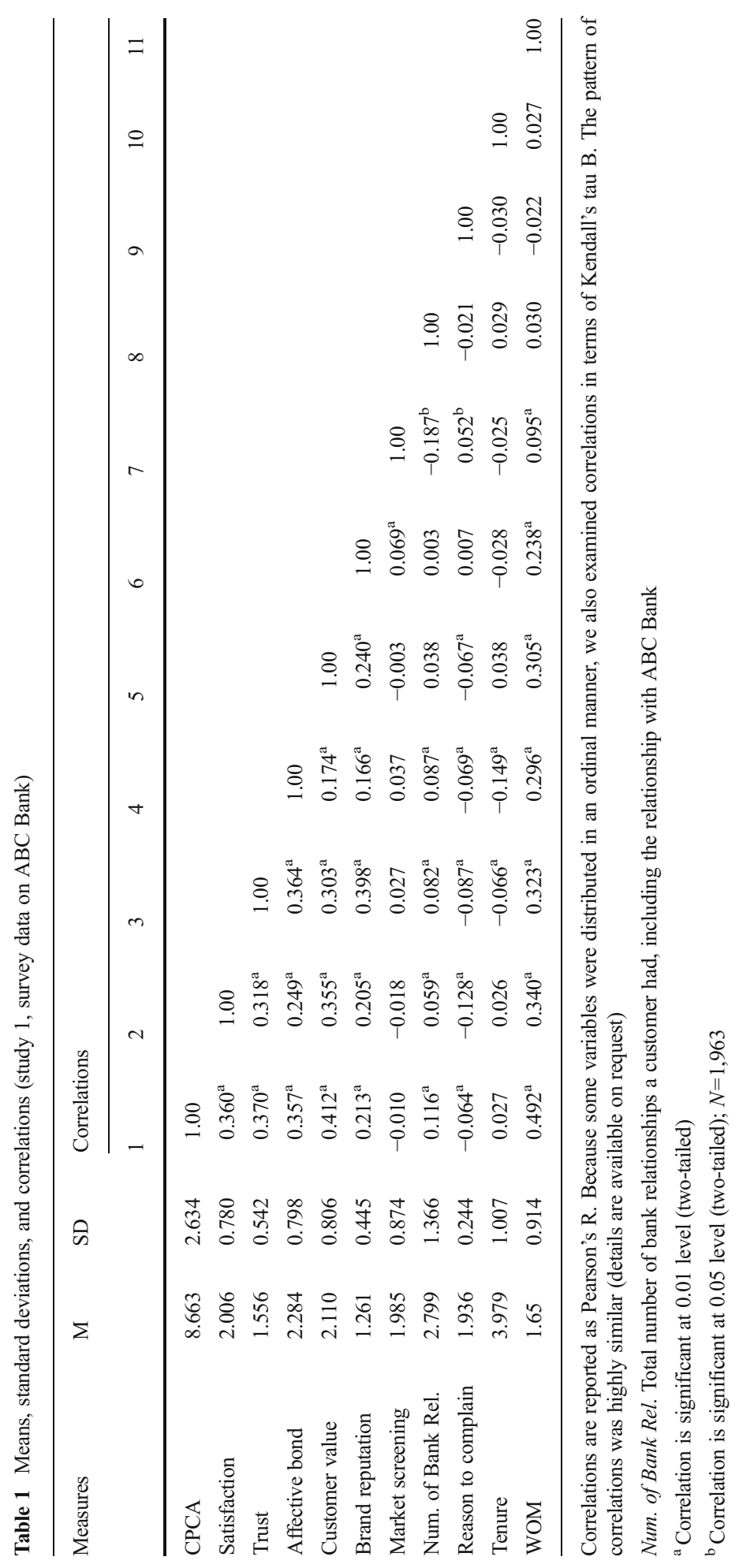


Table 2 presents the OLM results. The results for the overall model (see first column of Table 2) show that greater CPCA is associated with higher WOM intentions $\left(\beta^{S}{ }_{\text {CPCA }}=0.217, p<0.01\right)$, supporting $\mathrm{H}_{1}$. The main effect of satisfaction on WOM intentions is not significant $(p=0.16)$. However, the CPCA-by-satisfaction interaction is significant and positive $\left(\beta_{\text {CPCA } \times \text { Satis }}^{S}=0.348, p<0.01\right)$. The positive coefficient for the interaction suggests that both CPCA and satisfaction remain positive in their effect on WOM intentions but that the magnitude of CPCA's impact on WOM intentions changes across levels of satisfaction. As the literature recommends (Hoetker 2007), we re-ran the model across levels of satisfaction to better understand the interrelationships among CPCA, satisfaction, and WOM intentions. The results for each level of satisfaction appear in the second, third, and fourth columns of Table 2. At each level, the effect of CPCA on WOM intentions is positive and significant $(p<0.01)$. Notably, the impact of CPCA on WOM intentions is greater for lower levels of satisfaction than for the highest level of satisfaction $\left(\beta^{S}{ }_{\text {CPCA Complete Satis }}=0.368\right.$ vs. $\beta^{S}{ }_{\text {CPCA Dissatis }}=$ 0.498). These results support $\mathrm{H}_{2}{ }^{3}{ }^{4}$

\subsection{Discussion}

Study 1 reveals a positive association between CPCA and WOM intentions $\left(\mathrm{H}_{1}\right)$. Furthermore, in support of the interaction hypothesis $\left(\mathrm{H}_{2}\right)$, the impact of CPCA on WOM intentions depends on the level of satisfaction, with CPCA having a larger impact at lower levels of satisfaction. Less-satisfied customers particularly weigh CPCA when considering whether to spread positive WOM. Notably, brand reputation $\left(\beta_{\text {Brand Reputation }}^{S}=0.073, p<0.01\right)$ and market screening $\left(\beta_{\text {Market Screen }}^{S}=0.099, p<0.01\right)$ also positively influence WOM intentions. These two effects provide further evidence that social cognition and the firm's competitive context influence WOM, beyond established antecedents of loyalty intentions.

Study 1 demonstrates a novel CPCA-by-satisfaction interaction and its influence on WOM intentions. However, because the data came from customers of a single company, our findings may be influenced by ABC Bank's history, the industry context, or both. Therefore, study 2 tests our predictions in another country (USA), in another industry and across multiple firms (car insurance providers), and using a different methodology (experiment).

\footnotetext{
${ }^{3}$ We also examined the results when CPCA is omitted by running a restricted model (OLM without CPCA). Two insights emerged. First, eliminating CPCA results in a considerable drop in McKelvey and Zavoina's $R^{2}$ in the equation. Second, in the absence of CPCA, satisfaction is statistically significant. However, when CPCA is controlled for, satisfaction is rendered nonsignificant. This finding suggests that the omission of CPCA fundamentally alters the conclusions about the relationships between satisfaction and WOM intentions. In an additional analysis, we explored a potential nonlinear effect by adding a satisfaction ${ }^{2}$ variable to the model. The coefficient for this satisfaction ${ }^{2}$ variable was nonsignificant $(p>0.17)$. Adding this variable did not alter the pattern of our hypothesized effects; the CPCA main effect remained significant $\left(p<0.01 ; \mathrm{H}_{1}\right)$, and the satisfaction-by-CPCA interaction term also remained significant $\left(p<0.05 ; \mathrm{H}_{2}\right)$.

${ }^{4}$ Because the wording of the value item included the word "satisfied" (see Appendix 1), we explored whether the value variable may have influenced our results. Therefore, we re-ran our analyses without the value variable. The corresponding results regarding our hypothesized effects were highly similar. That is, the main effect of CPCA on WOM intentions was still significant, and the CPCA-by-satisfaction interaction also remained significant (this is true for studies 1 and 2). In summary, even in the absence of value, the results support $\mathrm{H}_{1}$ and $\mathrm{H}_{2}$.
} 


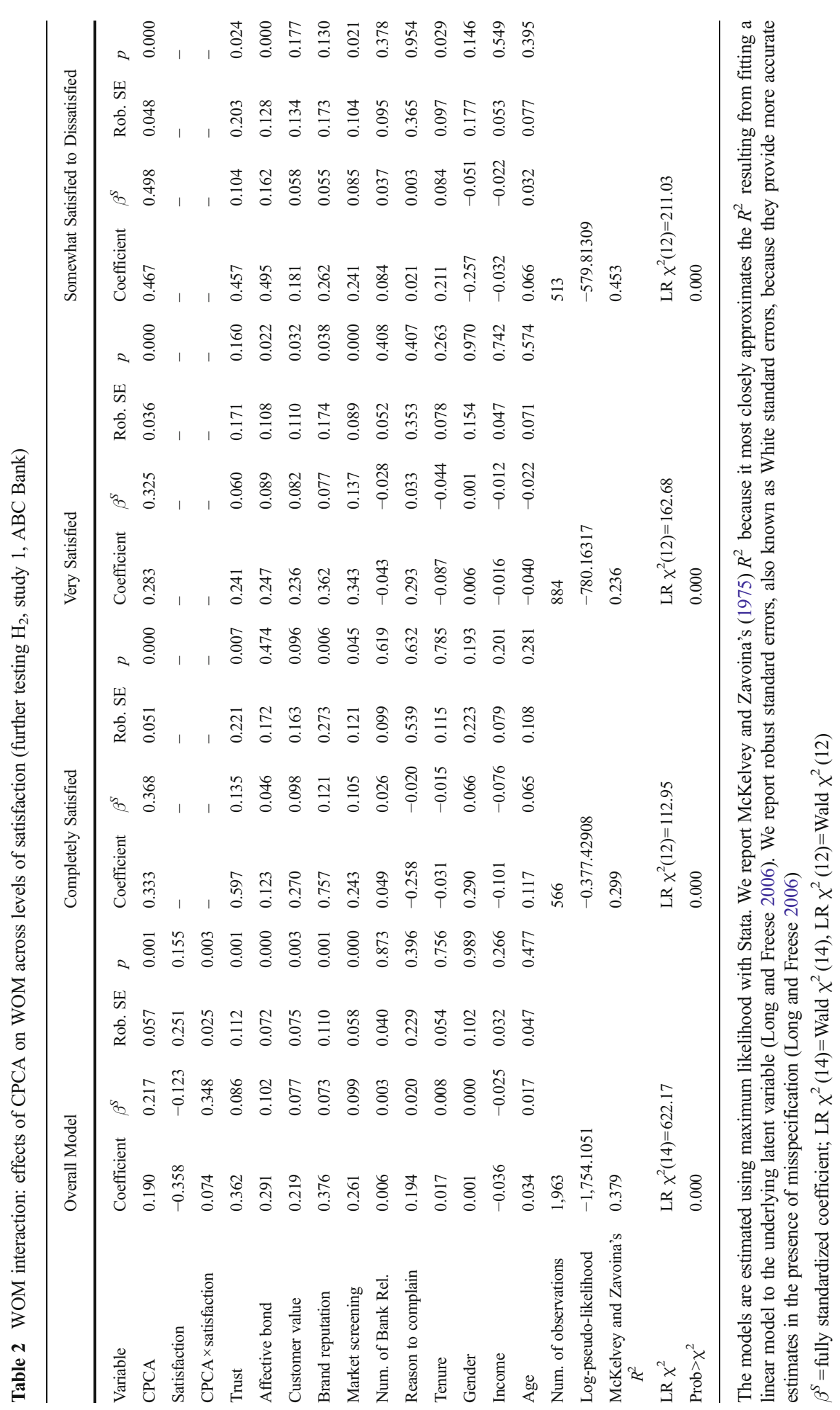




\section{Study 2: Experimental study on car insurance services}

Study 2 further investigates the interplay of CPCA, satisfaction, and WOM intentions. To provide evidence of causality, study 2 manipulates CPCA in an experimental design. ${ }^{5}$

\subsection{Research design}

Our study design is adapted from research in psychology on how perceptions of attractive alternatives interfere with existing relationships. Specifically, this research measures how people assess their current relationship and then it exposes them to an alternative partner, which is manipulated to be more or less attractive (Johnson and Rusbult 1989; Lydon, Fitzsimons, and Naidoo 2003). Accordingly, our experiment was a three-group (CPCA, superior/comparable/inferior) between-subjects design, with satisfaction as a measured covariate. The analysis included a similar set of covariates as in study 1 (see Appendix 2). ${ }^{6}$ Participants were 491 consumers in the USA who are members of a paid online panel (45.3\% female; median age, 25-34 years). As a result of missing responses or participants failing attention filters, the analyses included 461 respondents.

All participants first completed a questionnaire evaluating their actual car insurance company. They then read a manipulated Consumer Reports study on the competitiveness of car insurance companies (Kirmani and Zhu 2007). We held all information constant except for the CPCA manipulation (Appendix 3). Participants were randomly assigned to one of three CPCA conditions. In the superior condition $(N=149)$, a caption indicated that Consumer Reports found the focal insurance company superior on the three CPCA dimensions; in the comparable condition $(N=154)$, the company was equal, and, in the inferior condition $(N=158)$, it was inferior on the three dimensions. After reading about how their own insurance company performed in the Consumer Reports study, participants indicated their WOM intentions and responded to manipulation checks; they then were debriefed and exited the questionnaire.

\subsection{Results}

Table 3 provides the descriptive statistics and correlations, which were consistent with study 1 and prior research.

Manipulation checks Appendix 2 displays the items we used as manipulation checks. CPCA ratings were higher than in any other condition when superiority was manipulated $\left(M_{\text {Superior }}=23.69[\mathrm{SD}=3.96]\right.$ vs. $M_{\text {Comparable }}=17.74[\mathrm{SD}=3.48] ; F_{(1,300)}=4.64$, $p<0.001) ; M_{\text {Superior }}=23.69[\mathrm{SD}=3.96]$ vs. $M_{\text {Inferior }}=15.69[\mathrm{SD}=7.26] ; F_{(1,305)}=59.69$, $p<0.001)$. Moreover, CPCA ratings were higher for the comparable versus inferior condition $\left(M_{\text {Comparable }}=17.74[\mathrm{SD}=3.48]\right.$ vs. $M_{\text {Inferior }}=15.69[\mathrm{SD}=7.26] ; F_{(1,309)}=$ $88.37, p<0.001)$. Thus, our manipulation succeeded as intended.

\footnotetext{
${ }^{5}$ We are grateful to one of the reviewers for suggesting an experimental study to demonstrate causality.

6 "Number of relationships" was not included as a covariate because consumers work with only one car insurance company per vehicle (notably, this variable also had no significant effect in study $1 ; p>0.85$ ).
} 


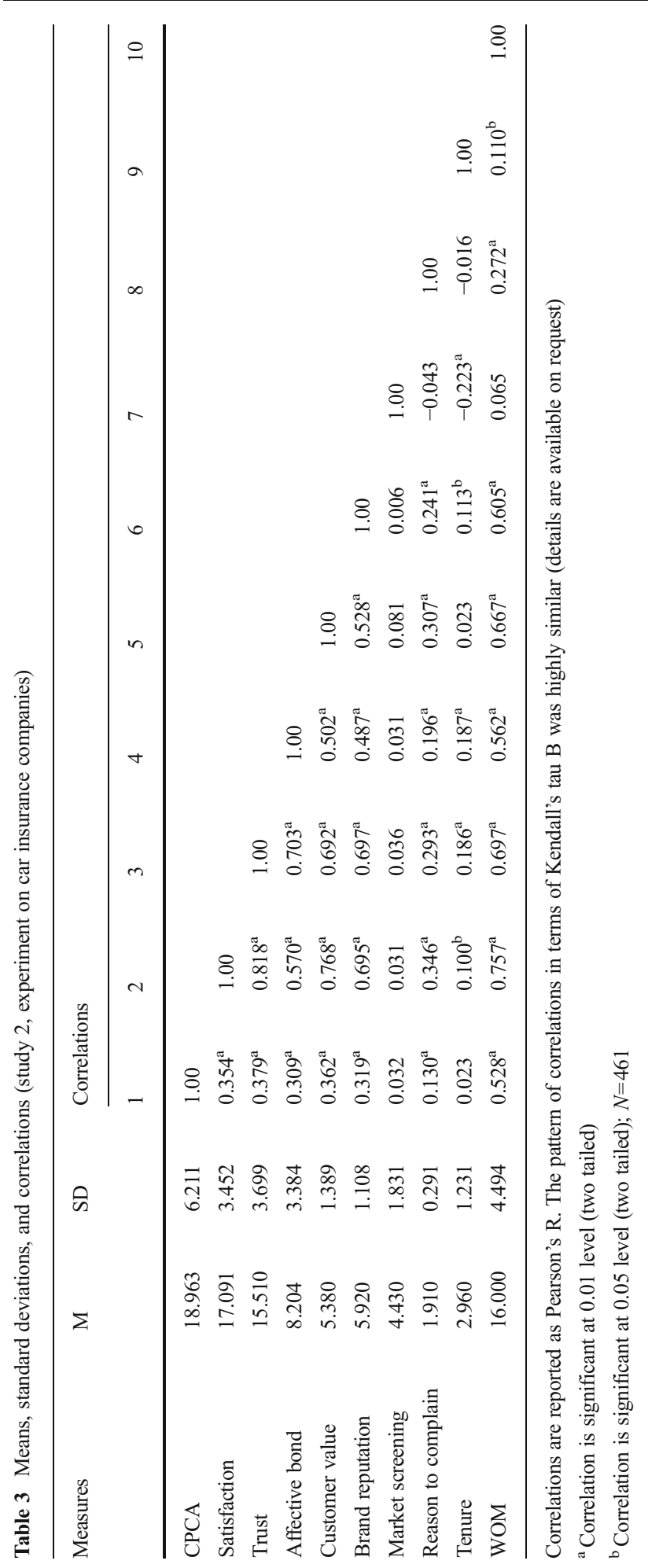


WOM intentions We conducted an analysis of covariance (ANCOVA) with WOM intentions as the dependent variable, CPCA as the manipulated factor, and satisfaction as the measured covariate $\left(F_{(15,445)}=64.34, p<0.001 ; \eta_{p}{ }^{2}=0.684\right)$.

As Table 4 displays, the ANCOVA revealed a significant main effect of CPCA on WOM intentions $\left(F_{(2,445)}=12.49, p<0.001 ; \eta_{p}{ }^{2}=0.053\right)$, and of satisfaction on WOM intentions $\left(F_{(1,445)}=56.54, p<0.001 ; \eta_{p}{ }^{2}=0.113\right)$. As expected, the CPCA-by-satisfaction interaction was significant $\left(F_{(2,445)}=5.85, p<0.01 ; \eta_{p}{ }^{2}=0.026\right)$. These results provide support for $\mathrm{H}_{1}$ and tentative support for $\mathrm{H}_{2}$. The means of WOM intentions were ordered as expected across the three CPCA levels. Customers in the superior condition reported the highest mean $\left(M_{\mathrm{WOMI}}=16.97\right)$, customers in the equal condition reported a lower mean $\left(M_{\mathrm{WOMI}}=16.10\right)$, and customers in the inferior condition reported the lowest mean $\left(M_{\mathrm{WOMI}}=14.99\right)$ of WOM intentions. To evaluate pairwise differences among these means, we conducted follow-up tests. These tests showed that the superior CPCA condition was significantly different from the inferior condition $\left(F_{(1,293)}=21.72\right.$, $\left.p<0.001 ; \eta_{p}{ }^{2}=0.069\right)$ and marginally different from the equal condition $\left(F_{(1,289)}=2.82\right.$, $\left.p<0.10 ; \eta_{p}{ }^{2}=0.010\right)$. Moreover, the equal condition was significantly different from the inferior condition $\left(F_{(1,298)}=9.75, p<0.01 ; \eta_{p}{ }^{2}=0.032\right)$. Finally, to examine whether the impact of CPCA on WOM intentions changes across levels of satisfaction, we grouped customers into three segments according to their (low, medium, or high) satisfaction and re-ran the model for the respective levels (Hoetker 2007). ${ }^{7}$ Examining the corresponding coefficients, we found that CPCA's impact on WOM intentions was greater at lower levels of satisfaction (CPCA for low satisfaction $\left(F_{(2,128)}=17.73, p<0.001 ; \eta_{p}{ }^{2}=0.217\right)$, CPCA for medium satisfaction $\left(F_{(2,144)}=4.04, p<0.05 ; \eta_{p}{ }^{2}=0.053\right)$, and CPCA for high satisfaction $\left.\left(F_{(2,150)}=7.22, p<0.01 ; \eta_{p}{ }^{2}=0.088\right)\right)$. These results support $\mathrm{H}_{2}$.

\subsection{Discussion}

Study 2 explored the extent to which results from study 1 generalize across industry (banks vs. car insurance), country (Germany vs. USA), and empirical method (survey vs. experiment). In doing so, study 2 replicates the core findings from study 1 , providing further evidence that CPCA plays an important role in shaping WOM intentions. As found in study 1, greater CPCA is associated with higher intentions to spread positive WOM, and this impact of CPCA was statistically significant beyond the significant main effect of satisfaction. Turning to the interaction, we again find support for $\mathrm{H}_{2}$; CPCA's positive influence on WOM intentions is greater at lower levels of satisfaction. These results - consistent with our theorizing - show that when it comes to WOM intentions, decreasing satisfaction levels trigger deliberate customer reflections on the advantage firms might (not) offer over their competitors.

\section{Conclusion}

Although a firm's competitive context is inextricably linked to its aspirations for customer loyalty, little relationship marketing research has examined how competition

\footnotetext{
${ }^{7}$ These analyses controlled for all covariates displayed in Table 3; details are available on request.
} 
Table 4 ANCOVA results (study 2, experiment on car insurance companies)

\begin{tabular}{llll}
\hline Descriptive statistics & & & \\
Condition/group & $\mathrm{M}$ & $\mathrm{SD}$ & $N$ \\
Superior & 16.97 & 3.94 & 149 \\
Comparable & 16.10 & 4.03 & 154 \\
Inferior & 14.99 & 5.18 & 158 \\
ANCOVA: tests of between-subjects effects & & & \\
Variable & $F$ & $p$ & $\eta_{p}^{2}$ \\
CPCA & 12.49 & 0.000 & 0.05 \\
Satisfaction & 56.54 & 0.000 & 0.11 \\
CPCA $\times$ satisfaction & 5.85 & 0.003 & 0.03 \\
Trust & 1.05 & 0.306 & 0.00 \\
Affective bond & 15.06 & 0.000 & 0.03 \\
Customer value & 13.90 & 0.000 & 0.03 \\
Brand reputation & 7.89 & 0.005 & 0.02 \\
Market screening & 3.73 & 0.054 & 0.01 \\
Reason to complain & 0.07 & 0.792 & 0.00 \\
Tenure & 0.01 & 0.945 & 0.00 \\
Gender & 1.35 & 0.247 & 0.00 \\
Income & 0.63 & 0.427 & 0.00 \\
Age & 6.25 & 0.013 & 0.01 \\
Intercept & 10.46 & 0.001 & 0.02 \\
\hline
\end{tabular}

Dependent variable - WOM intentions, measured with the three items displayed in Appendix 1

influences WOM intentions. Because WOM intentions are linked to firm performance (Kamakura et al. 2002), identifying new mechanisms that help better explain customers' referral intentions is crucial to marketers. The theoretical goal underlying the concept of CPCA is to capture customer assessments of a firm relative to its competitors, because consumers evaluate companies in a context-dependent manner (Posavac et al. 2005; Tversky and Simonson 1993). The analyses demonstrate that accounting for CPCA is fundamental for better predicting WOM intentions, beyond established loyalty drivers (e.g., satisfaction and trust). CPCA plays an important role in shaping WOM intentions across two industries, countries, and research methods. As such, our research points to the need for a stronger emphasis on the influence of a firm's competitive context on customer loyalty mechanisms (Boulding et al. 2005; Kumar et al. 2006). These results have important theoretical and managerial implications.

Theoretical implications Satisfaction is a central determinant of WOM (de Matos and Rossi 2008), but satisfied customers are not always a firm's dominant advocates (Brown et al. 2005). Drawing upon social cognition research, we show that CPCA affects WOM intentions, beyond satisfaction. Furthermore, the predicted CPCA-bysatisfaction interaction emerges in both industries. In each study, the CPCA coefficient is larger at lower levels of satisfaction. From a theoretical perspective, these findings 
show that CPCA contributes to our understanding of why people recommend a firm. Consistent with work on the role of self-promotion as a motive for WOM (Chung and Darke 2006; Wojnicki and Godes 2008), our findings underscore the need for marketers to better consider the social motives (e.g., self-promotion) that distinguish WOM intentions from nonsocial loyalty indicators (e.g., repurchase intentions). In summary, given its role in shaping WOM intentions, theoretical frameworks in marketing should include the notion of CPCA as a distinct antecedent of consumer referrals and further explore the possibility that satisfaction plays a more contingency-related role regarding WOM than prior research has suggested.

Managerial implications This research provides managers with actionable insights. First, it reveals that measuring CPCA is a necessity for firms aiming to understand WOM intentions. Although many companies routinely collect substantial information about consumers, insights into customers' perceptions of competing firms are often sparse. Lacking this information, firms may manage customer relationships with a limited, inward view (Kumar et al. 2006). Our findings suggest that companies should include measures of CPCA in their market research to better predict WOM intentions. Second, managers can use CPCA to identify the consumers who have a particularly high propensity to recommend the firm-information crucial for the efficiency and effectiveness of WOM-seeding campaigns (Libai et al. 2013). When designing WOM/buzz campaigns, marketers should not recruit only highly satisfied customers. Rather, they should attract customers with high CPCA scores because they are the most willing to engage in positive WOM. Finally, managers can use CPCA measures to solicit valuable feedback not only from current customers but also from potential or lost customers; as such, CPCA provides insights into why these segments of consumers may not recommend or patronize the firm.

Limitations and further research Our work has limitations that create opportunities for further research. First, we show the effect of CPCA on WOM intentions across two industries and two countries, based on survey and experimental data. Extending our work, researchers might contrast the association of CPCA with WOM intentions versus WOM behavior. Second, we study positive WOM, but not negative WOM. That is, consistent with the considerable managerial focus on positive WOM, we focus on consumer intentions to recommend a firm, but our data did not capture consumer intentions to spread negative WOM. Further research should study how the interplay between satisfaction and CPCA may trigger negatively-valenced WOM. Third, longitudinal analyses would enable researchers to track why CPCA changes (e.g., which events or marketing interventions shift CPCA levels?). Fourth, our work does not reveal the underlying psychological process related to $\mathrm{CPCA}$; however, our results suggest that examining this process in detail is a promising research opportunity. Finally, another fruitful perspective is to study additional moderators (beyond satisfaction) with which CPCA might interact to influence customer loyalty (e.g., consumers' variety seeking and switching costs). ${ }^{8}$

\footnotetext{
${ }^{8}$ We are grateful to one of the reviewers for suggesting this avenue for further research.
} 
Acknowledgments The authors are grateful to the editor and the two anonymous reviewers for the constructive and supportive feedback. Moreover, they thank Ruth Bolton, Mark Houston, Mike Hutt, and Maura Scott for helpful comments on earlier versions of this paper.

\section{Appendix 1 Measurement of variables (study 1)}

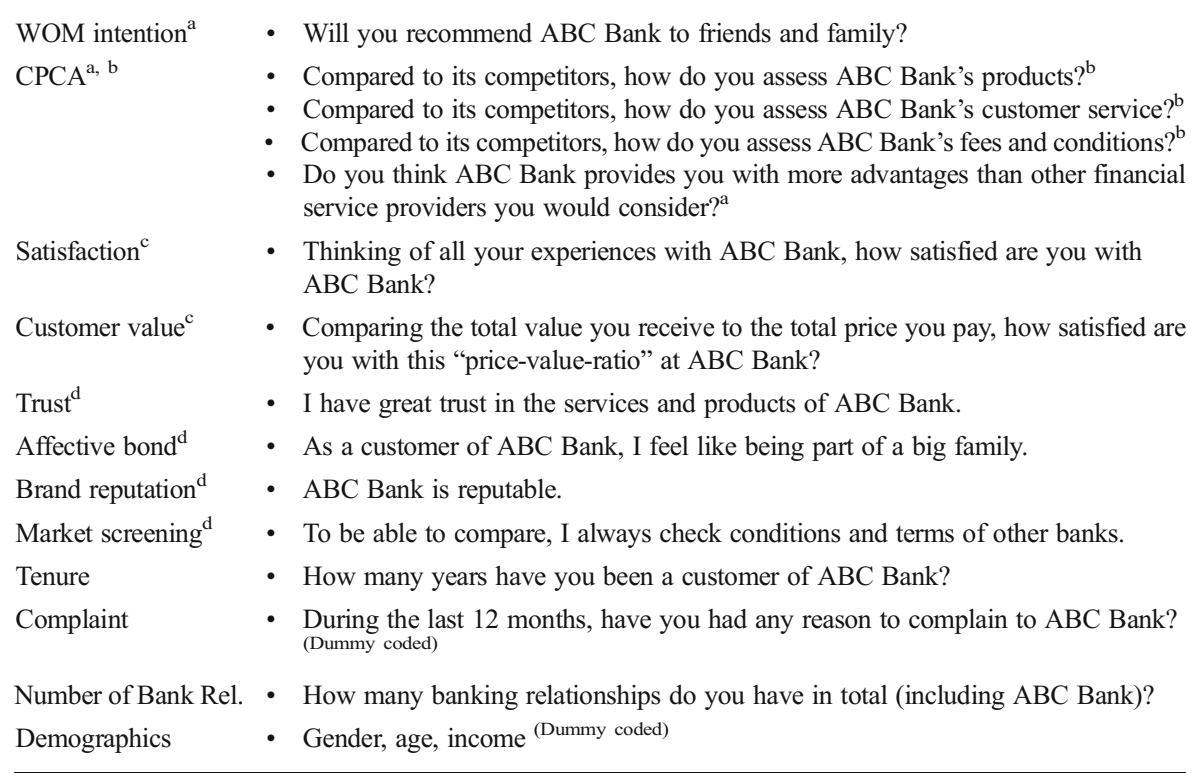

For study 1 , the collaborating market research firm worded the corresponding measures in line with the approach in all its surveys. Therefore, all variables in study 1 are coded such that lower scores suggest a more positive assessment by the consumer. The authors did not have any influence on the items or the measurement scales used and - consequently - some of the measures and their response categories are non-standard relative to prior scholarly marketing research. Importantly, however, study 2 uses measures from the academic marketing literature (e.g., seven-point Likert-type scales, coded from "strongly disagree" to "strongly agree") and the results across studies 1 and 2 are highly consistent. Therefore, the nonstandard measurement of variables in study 1 does not reasonably explain the results of this study

${ }^{a}$ Variable measured on a five-point Likert-type scale $(1=$ definitely, $5=$ definitely not $)$

${ }^{\mathrm{b}}$ Variable measured on a five-point Likert-type scale $(1=$ far better, $5=$ far worse $)$

${ }^{\mathrm{c}}$ Variable measured on a five-point scale $(1=$ completely satisfied, $5=$ dissatisfied $)$

${ }^{\mathrm{d}}$ Variable measured on a four-point Likert-type scale $(1=$ completely agree, $4=$ completely disagree $)$

\section{Appendix 2 Measurement of variables (study 2)}

\begin{tabular}{|c|c|c|}
\hline Construct & Measure & Source \\
\hline $\begin{array}{l}\text { WOM intention }{ }^{\mathrm{a}} \\
\text { Coefficent alpha: } 0.96\end{array}$ & $\begin{array}{l}\text { - How likely are you to tell others positive things about } \\
\text { (company)? } \\
\text { - If your friends were looking for car insurance, how likely } \\
\text { are you to tell them about (company)? } \\
\text { - If you were helping a colleague make a decision on what } \\
\text { car insurance to get, how likely are you to recommend } \\
\text { (company)? }\end{array}$ & $\begin{array}{l}\text { Brown et al. (2005); } \\
\text { Zeithaml et al. } \\
\text { (1996) }\end{array}$ \\
\hline $\begin{array}{l}\mathrm{CPCA}^{\mathrm{b}, \mathrm{c}} \\
\text { (manipulation checks) }\end{array}$ & $\begin{array}{l}\text { The Consumer Reports study found (company) to be } \\
\text { superior/comparable/inferior relative to its competitors. }\end{array}$ & \\
\hline
\end{tabular}




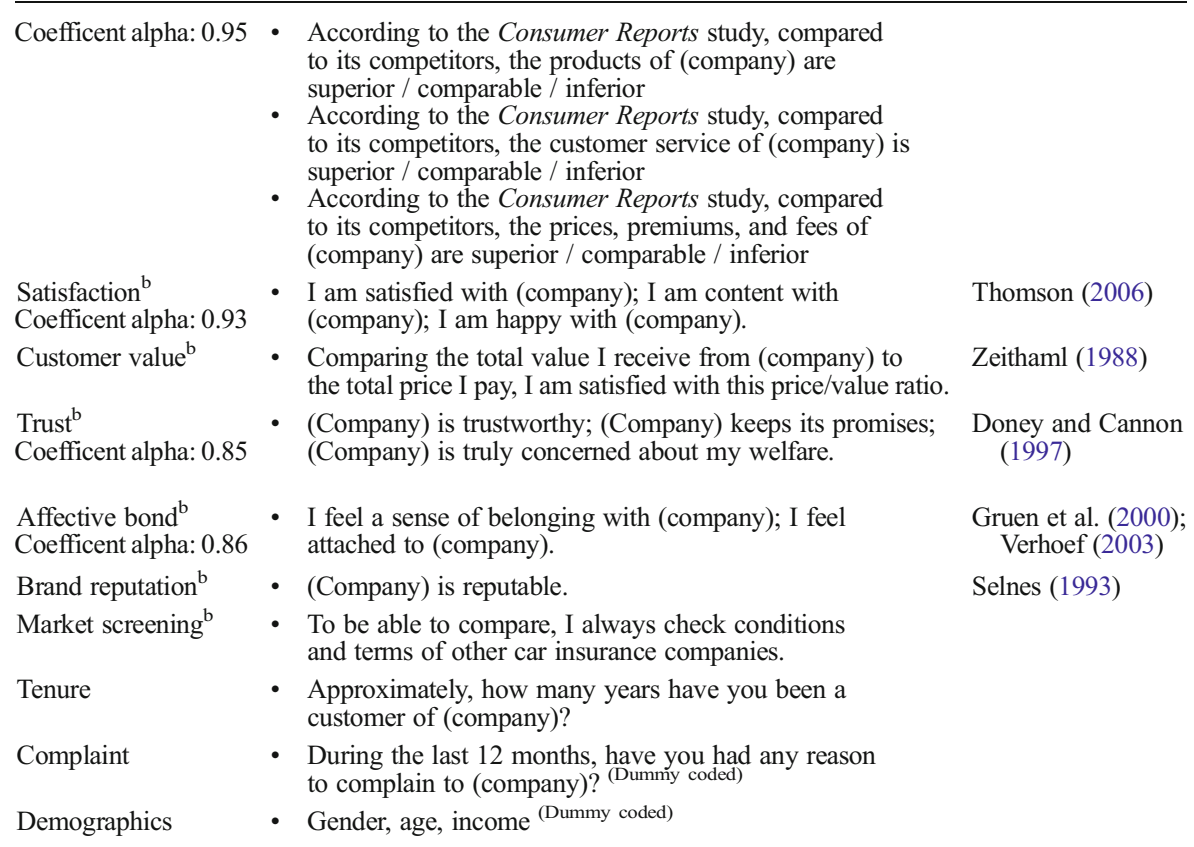

\footnotetext{
${ }^{\mathrm{a}}$ Variable measured on a seven-point Likert-type scale ( $1=$ very unlikely, $7=$ very likely $)$

${ }^{\mathrm{b}}$ Variable measured on a seven-point Likert-type scale $(1=$ strongly disagree; $7=$ strongly agree $)$

${ }^{c}$ Variable measured on a seven-point Likert-type scale ( $1=$ by far inferior to competitors; $7=$ by far superior to competitors)
}

\section{Appendix 3 Manipulation of CPCA (as used in study 2, "superior condition")}

At this point, you might be interested to learn about a new study on the competitiveness of car insurance companies published by Consumer Reports. This study revealed the three following findings regarding YOUR insurance company (i.e., insurance brand name was inserted here):

- Finding 1: [Insurance brand] offers superior insurance products relative to its competitors.

- Finding 2: [Insurance brand] offers superior customer service relative to its competitors.

- Finding 3: [Insurance brand] offers superior prices, premiums, and fees relative to its competitors.

In sum: According to this study, [insurance brand] is superior relative to its competitors. 


\section{Overall assessment relative to all competitors}

\section{- $\theta$ O $\ominus$ \\ BETTER $<<\langle<\rangle>>>$ WORSE \\ THAN COMPETITORS}

\begin{tabular}{|l|c|}
\hline Insurance Products & $\bullet$ \\
\hline Customer Service & $\bullet$ \\
\hline Prices, Premiums, and Fees & $\bullet$ \\
\hline
\end{tabular}

In the comparable and inferior conditions, the word "superior" was replaced by "comparable" and "inferior," respectively. In the graphic, the three visual markers were placed accordingly below the center dot (comparable condition) and below the right dot (inferior condition).

\section{References}

Anderson, E. W. (1998). Customer satisfaction and word of mouth. Journal of Service Research, 1(1), 5-17. Berger, J. \& Iyengar, R. (2012). How interest shapes word-of-mouth over different channels. Working paper, http://ssrn.com/abstract=2013141. Accessed 22 August 2012.

Boulding, W., Staelin, R., Ehret, M., \& Johnston, W. J. (2005). A customer relationship management roadmap. Journal of Marketing, 69(4), 155-166.

Brown, T. J., Barry, T. E., Dacin, P. A., \& Gunst, R. F. (2005). Spreading the word: investigating antecedents of consumers' positive word-of-mouth intentions and behaviors in a retailing context. Journal of the Academy of Marketing Science, 33(2), 123-138.

Chung, C. M. Y., \& Darke, P. R. (2006). The consumer as advocate: self-relevance, culture, and word-ofmouth. Marketing Letters, 17(4), 269-279.

Day, G. S., \& Wensley, R. (1988). Assessing advantage: a framework for diagnosing competitive superiority. Journal of Marketing, 52(2), 1-20.

de Matos, C. A., \& Rossi, C. A. V. (2008). Word-of-mouth communications in marketing: a meta-analytic review of the antecedents and moderators. Journal of the Academy of Marketing Science, 36(4), 578-596.

Dick, A. S., \& Basu, K. (1994). Customer loyalty: toward an integrated conceptual framework. Journal of the Academy of Marketing Science, 22(2), 99-113.

Doney, P. M., \& Cannon, J. P. (1997). An examination of the nature of trust in buyer-seller relationships. Journal of Marketing, 61(2), 35-51.

Duncan, J. W., Ginter, P. M., \& Swayne, L. E. (1998). Competitive advantage and internal organizational assessment. Academy of Management Executive, 12(3), 6-16.

Gale, B. T. (1994). Managing customer value: Creating quality and service that customers can see. New York: Free Press.

Garbarino, E., \& Johnson, M. S. (1999). The different roles of satisfaction, trust, and commitment in customer relationships. Journal of Marketing, 63(2), 70-87.

Greene, W. H. (2003). Econometric analysis (5th ed.). Upper Saddle River: Prentice Hall. 
Gruen, T. W., Summers, J. O., \& Acito, F. (2000). Relationship marketing activities, commitment, and membership behaviors in professional associations. Journal of Marketing, 64(3), 34 49.

Hoetker, G. (2007). The use of logit and probit models in strategic management research: critical issues. Strategic Management Journal, 28(4), 331-343.

Johnson, D. J., \& Rusbult, C. E. (1989). Resisting temptation: devaluation of alternative partners as a means of maintaining commitment in close relationships. Journal of Personality and Social Psychology, 57(6), 967-980.

Kamakura, W. A., Mittal, V., de Rosa, F., \& Mazzon, J. A. (2002). Assessing the service-profit chain. Marketing Science, 21(3), 294-317.

Kirmani, A., \& Zhu, J. (2007). Vigilant against manipulation: the effects of regulatory focus on the use of persuasion knowledge. Journal of Marketing Research, 44(4), 688-701.

Kumar, V., Lemon, K. N., \& Parasuraman, A. (2006). Managing customers for value: an overview and research agenda. Journal of Service Research, 9(2), 87-94.

Liao, T. F. (1994). Interpreting probability models. Sage University Paper Series on Quantitative applications in the social sciences. Thousand Oaks: Sage.

Libai, B., Muller, E., \& Peres, R. (2013). Decomposing the value of word-of-mouth seeding programs: acceleration versus expansion. Journal of Marketing Research, 50(2), 161-175.

Long, J. S. (1997). Regression models for categorical and limited dependent variables. Thousand Oaks: Sage.

Long, J. S., \& Freese, J. (2006). Regression models for categorical dependent variables using Stata (2nd ed.). College Station: Stata Press.

Lydon, J. E., Fitzsimons, G. M., \& Naidoo, L. (2003). Devaluation versus enhancement of attractive alternatives: a critical test using the calibration paradigm. Personality and Social Psychology Bulletin, 29(3), 349-359.

McKelvey, R. D., \& Zavoina, W. (1975). A statistical model for the analysis of ordinal level dependent variables. Journal of Mathematical Sociology, 4(1), 103-120.

Menard, S. (2002). Applied logistic regression analysis. Thousand Oaks: Sage.

Morgan, N. A., \& Rego, L. L. (2008). Can behavioral WOM measures provide insight into the Net Promoter ${ }^{(}$ concept of customer loyalty? Marketing Science, 27(3), 533-534.

Nunnally, J. C., \& Bernstein, H. (1994). Psychometric theory (3rd ed.). New York: McGraw-Hill.

Oliver, R. L. (1997). Satisfaction: A behavioral perspective on the consumer. New York: McGrawHill.

Ping, R. A., Jr. (1994). Does satisfaction moderate the association between alternative attractiveness and exit intention in a marketing channel? Journal of the Academy of Marketing Science, 22(4), 364-371.

Posavac, S. S., Kardes, F. R., Sanbonmatsu, D. M., \& Fitzsimons, G. J. (2005). Blissful insularity: When brands are judged in isolation from competitors. Marketing Letters, 16, 87-97.

Schlenker, B. R. (1980). Impression management: the self-concept, social identity, and interpersonal relations. Monterey: Brooks.

Selnes, F. (1993). An examination of the effect of product performance on brand reputation, satisfaction and loyalty. European Journal of Marketing, 27(9), 19-35.

Smith, A. K., \& Bolton, R. N. (1998). An experimental investigation of service failure and recovery: Paradox or peril? Journal of Service Research, 1(1), 65-81.

Stephen, A. T., \& Lehmann, D. R. (2009). Why do people transmit word-of-mouth? The effects of recipient and relationship characteristics on transmission behaviours. Working paper, Columbia University.

Thomson, M. (2006). Human brands: investigating antecedents to consumers' strong attachments to celebrities. Journal of Marketing, 70(3), 104-119.

Tversky, A., \& Simonson, I. (1993). Context-dependent preferences. Management Science, 39(10), 11791189.

Verhoef, P. (2003). Understanding the effect of customer relationship management efforts on customer retention and customer share development. Journal of Marketing, 67(4), 30-45.

Winship, C., \& Mare, R. D. (1984). Regression with ordinal variables. American Sociological Review, 49, 512-525.

Wojnicki, A. C., \& Godes, D. (2008). Word-of-mouth as self-enhancement. Harvard Business School, Marketing Research Paper No. 06-01.

Zeithaml, V. A. (1988). Customer perceptions of price, quality, and value: a means-end model and synthesis of evidence. Journal of Marketing, 52(3), 2-22.

Zeithaml, V. A., Berry, L. L., \& Parasuraman, A. (1993). The nature and determinants of consumer expectations of service. Journal of the Academy of Marketing Science, 21(1), 1-12.

Zeithaml, V. A., Berry, L. L., \& Parasuraman, A. (1996). The behavioral consequences of service quality. Journal of Marketing, 60(2), 31-46. 